\title{
New Trends in Anterior Cruciate Ligament Reconstruction: A Systematic Review of National Surveys of the Last 5 Years
}

\author{
Alberto Grassi ${ }^{1}$ Christian Carulli ${ }^{2}$ Matteo Innocenti ${ }^{2}$ Massimiliano Mosca ${ }^{1}$ Stefano Zaffagnini ${ }^{1}$ \\ Corrado Bait ${ }^{3}$ SIGASCOT Arthroscopy Committee
}

${ }_{1}$ II Clinica Ortopedica e Traumatologica, IRCSS Istituto Ortopedico Rizzoli, Bologna, Italy

2 Orthopaedic Clinic, Department of Surgery and Translational Medicine, University of Florence, Florence, Italy

3 Joint Surgery and Sport Medicine Unit, Istituto Clinico Villa Aprica, Como, Italy

Joints 2018;6:177-187.

\begin{abstract}
Address for correspondence Alberto Grassi, MD, II Clinica Ortopedica e Traumatologica, IRCSS Istituto Ortopedico Rizzoli, Via Pupilli 1, Bologna 40136, Italy (e-mail: alberto.grassi3@studio.unibo.it).
\end{abstract}

\begin{abstract}
Keywords

- anterior cruciate ligament

- reconstruction

- systematic review

- graft choice

- national survey
\end{abstract}

The purpose of this study was to analyze national surveys of orthopaedic surgeons on anterior cruciate ligament $(\mathrm{ACL})$ reconstruction to determine their preferences related to the preferred graft, femoral tunnel positioning, fixation and tensioning methods, antibiotic and anti-thromboembolic prophylaxis, and use of tourniquet and drains. A systematic search of PubMed, Web of Science, and Cochrane Library was performed. Inclusion criteria were surveys of ACL reconstruction trends and preferences published in the past 5 years (2011-2016), involving members of national societies of orthopaedics. Information regarding survey modalities, population surveyed, graft choice both in the general or in the athletic population, surgical technique, fixation, use of antibiotic, tourniquet, drains, and anti-thromboembolic prophylaxis was extracted. Eight national surveys were included from Europe (three), North or Latin America (three), and Asia (two). Overall, 7,420 questionnaires were sent, and 1,495 participants completed the survey (response rate ranging from 16 to $76.6 \%$ ). All surveys reported the hamstring tendon ( $\mathrm{HT}$ ) autograft as the preferred graft, ranging from 45 to $89 \%$ of the surveyed population, followed by bone-patellar tendon-bone (BPTB) graft (2-41\%) and allograft (2-17\%). Only two surveys focusing on graft choice in athletic population underlined how in high-demand sportive population the graft choices changes in favor of BPTB. Single-bundle reconstruction was the preferred surgical technique in the four surveys that investigated this issue. Five surveys were in favor of anteromedial (AM) portal and two in favor of trans-tibial technique. Suspension devices for femoral fixation were the preferred choice in all but one survey, while interference screws were the preferred method for tibial fixation. The two surveys that investigated graft tensioning were in favor of manual tensioning. The use of tourniquet, antibiotics, drains, and anti-thromboembolic prophylaxis were vaguely reported. A trend toward the preference of HT autograft was registered in all the surveys; however, sport participation has been highlighted as an important variable for increased use of BPTB. Single-bundle reconstruction with AM portal technique and suspension femoral received

September 28, 2017

accepted

August 10, 2018

published online

September 27, 2018
DOI https://doi.org/

10.1055/s-0038-1672157. ISSN 2282-4324.
Copyright (c) 2018 Georg Thieme Verlag License terms

KG Stuttgart - New York 
fixation and screws fixation for the tibia seem the preferred solution. Other variables such as tensioning, antibiotic, anti-thromboembolic prophylaxis, tourniquet use, and drains were investigated scarcely among the surveys; therefore, no clear trends could be delineated. This is a Level $\mathrm{V}$, systematic review of expert opinion study.

\section{Introduction}

Anterior cruciate ligament (ACL) reconstruction is a successful procedure independently by the choice of graft, surgical technique, and fixation devices. ${ }^{1}$ Nevertheless, to date there is no consensus about the gold standard method for ACL reconstruction. Even if recent clinical evidence showed that both hamstring tendons (HT) and bone-patellar tendon-bone(BPTB) have advantages and drawbacks, there is still not an ideal graft reported in literature. ${ }^{2-4}$ Similarly, several methods of femoral and tibial tunnel placement have been proposed during the last decades, with no clear superiority of one technique on another. ${ }^{5-10}$ Finally, many metallic and soft absorbable and non-absorbable fixation devices have been released in the market over the years, showing comparable clinical outcomes. ${ }^{11,12}$

Several surveys have been recently performed with the aim to delineate national trends on the above-mentioned topics, as proper indications and precise surgical techniques are crucial to achieve a postoperative stability and a full return to sports activity. Although every surgeon plans his work based on experience and scientific evidence, we believe strongly important is the analysis of surveys to show the trends and to guide the choices of those surgeons who want to start performing this specific surgical procedure.

The purpose of the present study was to analyze national surveys of orthopaedic surgeons on ACL reconstruction to determine the surgical experience of participants to the surveys and their preferences related to the preferred graft, femoral tunnel positioning, fixation and tensioning methods, antibiotic and anti-thromboembolic prophylaxis, and use of drains.

The hypothesis of the study was that there are no differences in the choice of graft, surgical techniques, and fixation devices used for ACL reconstruction according to the selected national surveys.

\section{Methods}

As an initiative of the members of the Arthroscopy Committee of the Italian Society of Knee, Arthroscopy, Sport, Cartilage and Orthopaedic Technologies (SIGASCOT), the study design of this systematic review was elaborated to investigate the recent surgical trends in ACL reconstruction within worldwide national societies of orthopaedic surgeons.

\section{Search Strategy}

A systematic review was performed in accordance with the Preferred Reporting Items for Systematic reviews and MetaAnalysis (PRISMA) guidelines. ${ }^{13}$ A systematic search of the PubMed, Web of Science, and the Cochrane Library electronic databases was performed and updated until September 25, 2017. The search terms were mapped to Medical Subject Headings (MeSH) terms where possible. Search terms were entered under two topic: topic 1-(ACL) OR (anterior cruciate ligament); topic 2-(survey) OR (trends). Each topic was then combined with the 'AND' operator to produce the search strategy.

Two authors reviewed the title and abstract of each identified article to be selected. When the eligibility was unclear by title and abstract, the full text of the article was obtained and evaluated for eligibility.

\section{Selection Criteria}

Studies obtained from the search were included in the systematic review according to the specific inclusion and exclusion criteria. Inclusion criteria were surveys on ACL reconstruction trends and preferences, national surveys involving a national society of orthopaedic surgeons, report on the preferred graft for ACL reconstruction, surveys published in the past 5 years (2011-2016), and surveys published on peer-reviewed journals and written in English.

Exclusion criteria were as follows: lacking or equivocal data on graft preference (no answer or more than one answer available) and surveys involving members of different nations. In case of multiple surveys investigating the same population, only one survey was included in the review according to the following criteria: the most recent, the widest population, and the completeness of data regarding primary and secondary outcomes. The references of the relevant papers were screened to search additional studies to include in the review.

\section{Data Extraction}

The following data were obtained from the selected surveys: year and national society of the participants involved in the survey, number of sent surveys and following responses, and method of survey. The surveyed population was described considering professional status (dedicated fellowship and subspecialties), ACL procedures performed per year, and years of experience. Regarding surgical preferences, extracted data were graft choice, use of single- or double-bundle technique, preference for femoral tunnel drilling, fixation methods, and use of antibiotic and antithromboembolic prophylaxis, tourniquet, and drains.

\section{Quality Assessment}

The quality of the survey was evaluated using a five-item scoring system based on a binary outcome (yes|no) appositely developed for the purpose of this systematic review. It consisted of the following items: response rate $>50 \%$, surveyed members $>100$, systematic invitation of representative participants of the nation, surgical experience of surveyed members (ACL procedures per years and/or years 
of experience), and completeness of results presentation (all items reported as percentage, no charts).

\section{Results}

\section{Search Results}

After the initial search, 31 surveys related to ACL reconstruction were obtained. Thirteen papers were excluded because these had been published before 2011. Of the remaining 18 surveys, 2 were excluded because they evaluated the same population, ${ }^{14,15} 3$ because they reported the preference of members of multiple nations or international societies, ${ }^{16-18} 4$ were excluded because they evaluated the preferences for the reconstruction exclusively in athletes, ${ }^{19-22}$ and 1 was excluded because data regarding graft choice were not accurately reported. ${ }^{23}$ Finally, eight surveys were included in the final systematic review (-Fig. 1). ${ }^{24-31}$

\section{Surveys Methodologies and Populations Surveyed}

All except one survey were performed systematically inviting the members of a specific orthopaedic national society through a personal invitation via Internet. In these cases, the surgical preferences were collected through an online survey. Only Ambra et al directly invited the members of the national society to fill a paper survey during the society meeting. ${ }^{26}$ All surveys investigated the ACL reconstruction preferences related to an unspecific general population (-Table 1).

Three surveys evaluated European countries, three North and Latin American countries, and, the remaining two Asian countries. All except one ${ }^{26}$ surveyed the members of one or more national societies of orthopaedics or knee surgeons.

Overall, 7,420 questionnaires were sent, and 1,495 participants completed the survey, with a response rate ranging from 16.0 to $76.6 \%$. When reported, the average numbers of ACL performed per years was $<50$ and the surgical experience $<10$ years for the surveyed subjects. Three surveys reported also subspecialty in knee surgery for most of the surveyed (-Table 2 ).

\section{Quality Evaluation}

Despite only one survey had a response rate $>50 \%$, four (50\%) surveys collected the preferences of $>100$ orthopaedic surgeons. A systematic invitation of all surveyed populations was performed in seven (87.5\%) out of eight surveys. Also, the surgical experience in ACL reconstruction was investigated in $87.5 \%$ of the surveys; only one survey clearly presented all results of the proposed questions. The other seven surveys mostly utilized charts and figures for data presentation, providing imprecise or incomplete information related to several outcomes (-Table $\mathbf{3}$ ).

\section{Surgical Preferences}

Overall, all surveys reported HT autograft as the graft of choice for most of the surveyed participants, ranging from 45 to $89 \%$. Bone-patellar tendon-bone (BPTB) was the second preferred choice, ranging from 2 to $41 \%$ (-Fig. 2). The allograft was the first choice for 2 to $17 \%$ of the surveyed population. Two surveys focused on graft choice in athletic population. ${ }^{29,31}$ In one of them, BPBT was the first choice for $61 \%$ of surgeon in male high-demand athletes; ${ }^{29}$ HTs were the preferred choice for female athletes $(57 \%)$ in the same survey and the preferred choice overall in the second survey, albeit the use of BРTВ remained more frequent in highdemand athletes than in the others (49 vs. $45 \%$ ). ${ }^{31}$

Single-bundle reconstruction was the preferred technique in the four surveys that investigated this issue. ${ }^{24-27,29}$

Seven studies reported the technique for femoral tunnel drilling: five were in favor of anteromedial (AM) portal, $^{24,26,27,29,30}$ and the remaining two were in favor of trans-tibial technique. ${ }^{28,31}$

When reported, suspension systems for femoral fixation were the preferred choice in all but one survey, while screws was the preferred method for tibial fixation. Two surveys reported the preference of graft tensioning, which were in favor of manual tensioning. Two surveys reported agreement in the use of tourniquet for most of the surveyed surgeons, while no agreement was observed for antibiotic and anti-thromboembolic prophylaxis and the use of drains (-Table 4).

\section{Discussion}

This systematic review of national surveys about graft choice and surgical trends in ACL reconstruction was conducted considering restrictive inclusion and exclusion criteria.

We choose to perform such a rigorous survey because we all know that guidelines for the surgical management of $\mathrm{ACL}$ injuries are based on scientific findings rather than on expert opinion. Even more, we know how prospective randomized clinical trials (RCTs) are considered to provide the best quality of evidence in the medical literature and are definitely the source of data for systematic reviews and metaanalyses that guide clinical decision-making. The limit in ACL reconstruction is that adherence to evidence-based medicine is not always possible because high-quality evidence is not available or is inconclusive. ${ }^{32}$ Thus, the absence of a clear evidence leads to inconsistencies among surgeons' clinical practice, trends, and recommendations in the literature. ${ }^{16}$ According with such criteria, we were able to examined only eight studies despite the great number of studies published in the literature.

The most important finding reported in the present study is the preference of HT graft in all the nations, ranging from 45 to $95 \%$ of the clinicians surveyed. This global trend seems to reflect the general belief, confirmed by the Cochrane recommendations, of higher risk of anterior knee pain and extension loss using BPTB autografts, in spite of comparable results respect to HT autografts for knee stability. ${ }^{33}$ This finding is even more resounding when we have a look to the historical passage in graft choice from BPBT to HTs in the two biggest surveys performed such as the ESA and Canadian survey. Indeed in the United States, historical supporter of the BPTB, an inversion of the trend 


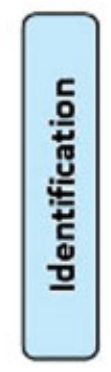

\section{Records identified through database searching}

- PubMed: 1262

- Web of Science: 570

- Cochrane: 96
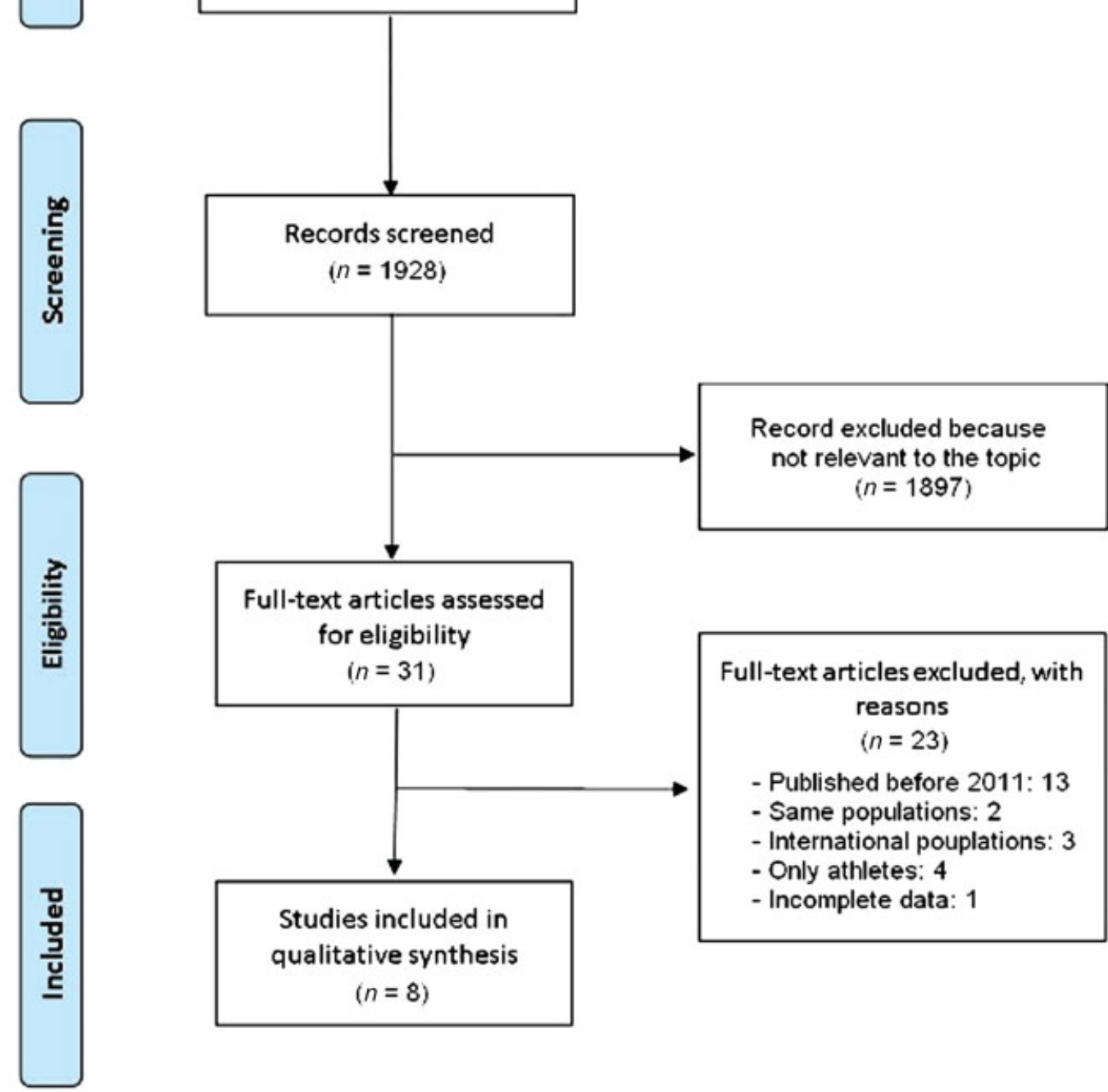

Fig. 1 Literature search flowchart according to the PRISMA guidelines. PRISMA, Preferred Reporting Items for Systematic reviews and MetaAnalysis.

has been registered in the most recent survey. In fact, surveys not included in this review, but conducted in the United States in 1999, 2001, and 2006, found that the use of BPTB autografts has progressively declined and that the use of HTs and allografts has risen, ${ }^{34}$ despite that until 2011, BPTB autograft was still considered the preferred choice. ${ }^{35-37}$ Also, the survey including the greatest number of participants, performed on an international population during the AAOS and EFORT 2011 meetings, revealed that HTs were the most popular graft choice (63\%), followed by BPTB $(26 \%)$ and allograft $(11 \%) .{ }^{16}$ As we previously under- lined, this variation occurs in the context of an increasing number of RCTs and meta-analyses documenting the strengths and limitations of both approaches with no consensus on the choice of one over the other. ${ }^{38-40}$ However, due to the recent evidences of higher failure rates with HT compared with BPTB autografts arisen form Scandinavian and US registries, ${ }^{41-43}$ it could be possible to assist to a new trend inversion in favor of BPTB in the future. Moreover, several surveys highlighted the sport participation of patients to influence the graft choice toward BPTB autograft. In fact, BPTB seems to be the preferred graft among 


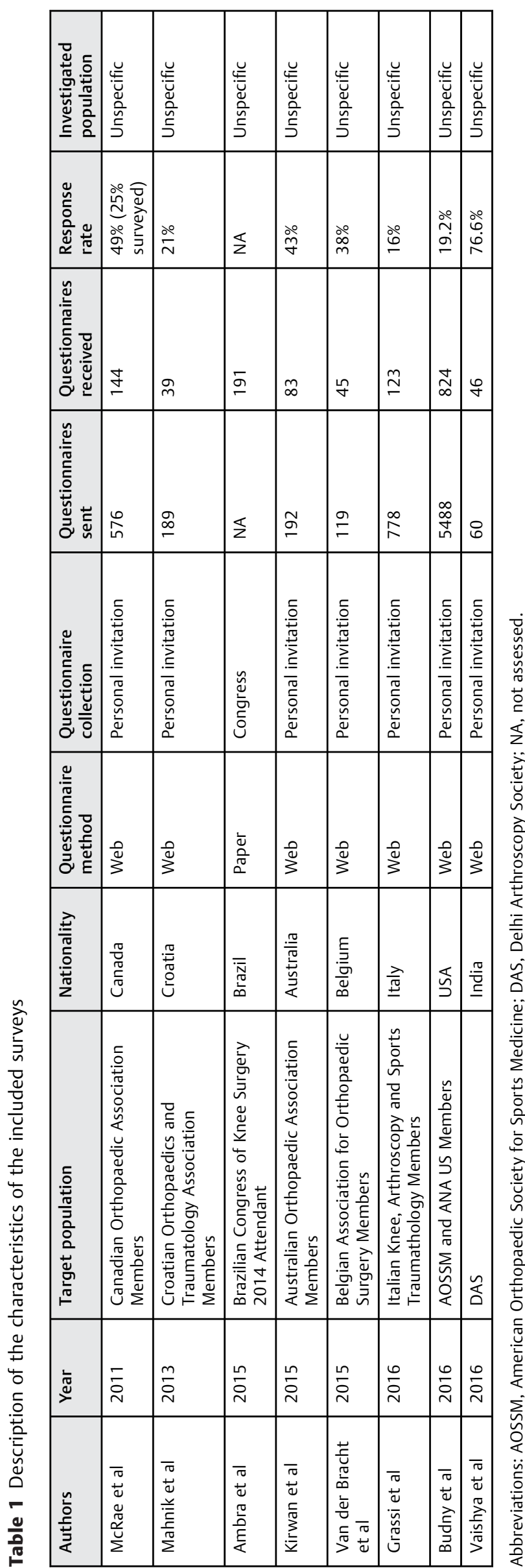

the National Basketball Association (NBA), ${ }^{22}$ National Football League (NFL), ${ }^{20}$ and Major League Soccer (MLS) athletes. ${ }^{21}$ Even in a survey conducted by Duquin et al, ${ }^{34}$ among the members of the American Orthopaedic Society for Sports Medicine (AOSSM), it was found that the preferred graft for ACL reconstruction was BPTB autograft (46\%) followed by HT (32\%) and allografts (22\%). The same concept has emerged from two of the surveys focusing on graft choice in athletic population included in our review. ${ }^{29,31}$ In the United States survey, ${ }^{29}$ BPBT was the first choice among $61 \%$ of surgeon in male high-demand athletes, whereas HTs remained the first choice for athletic women but with a lesser percentage than general population. ${ }^{29}$ As the United States surgeons, Italian surgeons preferences shift to a high percentage of BPTB graft when treating professional athletes compared with the percentage of BPBT used for general population, even if HTs still remain the preferred choice for Italian surgeons (42\%) regarding "sport and ACL reconstruction."14

Regarding the preferred technique for ACL reconstruction, single-bundle appeared the preferred choice for most of surgeons surveyed, probably because of the complexity of the double-bundle procedure in spite of a not proven superiority in terms of outcomes. ${ }^{44}$ Anyway, this choice seems to have more anatomical and biomechanical reasons than those simply related to the complexity of the surgical procedure itself.

Indeed ACL reconstruction has evolved considerably over the past 40 years, and just at the real begins in the 1980s, the gold standard technique was a trans-tibial, AM bundle reconstruction, the so called "mismatch" reconstruction (tibial posterolateral [PL] bundle attachment and femoral AM bundle origin). ${ }^{45-47}$ Even though this technique showed satisfactory and reliable clinical results over time, a certain amount of rotatory instability with a positive pivot shift test have been reported in up to $25 \%$ of cases. ${ }^{48-51}$ This lacking of rotational control was confirmed by biomechanical studies, ${ }^{51-53}$ and so in the 21 st century, we assisted to a shift on ACL reconstruction focusing more on anatomic reconstruction $^{51,54,55}$ with the double-bundle procedure. ${ }^{48,56,57}$ In the meanwhile, the better understanding of ACL anatomy and function has also led to modifications in single-bundle ACL surgery ${ }^{54} \mathrm{~A}$ single femoral tunnel positioned within the anatomic center of the native femoral footprint is supposed to recreate the function of both the AM and PL bundles, thus preventing clinical failure secondary to persistent instability. ${ }^{53,58-60}$

Among the studies investigating the technique for femoral tunnel drilling, most were in favor of AM portal technique. This could be due to the possible risk of suboptimal femoral tunnel placement using the trans-tibial technique when aiming to perform an anatomical singlebundle reconstruction. ${ }^{61}$ The AM portal technique resulted more popular among the youngest and less experienced surgeons probably because they started their practice during the popularization of the technique and because they could be less familiar with the standard trans-tibial technique, which seems to be progressively abandoned. 
182 Surveys of ACL Surgical Trends Grassi et al.

Table 2 Details of the clinical experience of the surveyed participants

\begin{tabular}{|c|c|c|c|c|}
\hline Authors & Year & Professional status & $A C L$ per year & Years of experience \\
\hline McRae et al & 2011 & NA & NA & 13.2 years (mean) \\
\hline \multirow[t]{2}{*}{ Mahnik et al } & 2013 & NA & $75 \%<50$ per year & $56 \%<10$ years of experience \\
\hline & & & $25 \%>50$ per year & $44 \%>10$ years of experience \\
\hline \multirow[t]{5}{*}{ Ambra et al } & 2015 & $80 \%$ knee surgeons & $3 \%<10$ per year & $45 \%<5$ years of experience \\
\hline & & $\begin{array}{l}15 \% \text { orthopaedic } \\
\text { surgeons }\end{array}$ & $13 \% 10-25$ per year & $25 \% 5-10$ years of experience \\
\hline & & $5 \%$ residents & $37 \%$ 25-60 per year & $\begin{array}{l}12 \% 10-15 \text { years of } \\
\text { experience }\end{array}$ \\
\hline & & & $28 \% 60-120$ per year & $18 \%>15$ years of experience \\
\hline & & & $19 \%>120$ per year & \\
\hline \multirow[t]{6}{*}{ Kirwan et al } & 2015 & NA & $6 \%<10$ per year & $10 \%<15$ years of experience \\
\hline & & & 10\% 10-20 per year & $16 \% 5-9$ years of experience \\
\hline & & & $20 \%$ 21-30 per year & $\begin{array}{l}19 \% 10-14 \text { years of } \\
\text { experience }\end{array}$ \\
\hline & & & $10 \% 31-40$ per year & $\begin{array}{l}13 \% 15-19 \text { years of } \\
\text { experience }\end{array}$ \\
\hline & & & $8 \% 41-50$ per year & $42 \%>20$ years of experience \\
\hline & & & $46 \%>50$ per year & \\
\hline \multirow[t]{5}{*}{ Van der Bracht et al } & 2015 & $29 \%$ knee surgeons & $2 \% 0-10$ per year & $27 \% 0-5$ years of experience \\
\hline & & $\begin{array}{l}56 \% \text { knee }+1 \text { other } \\
\text { joint surgeons }\end{array}$ & $22 \% 10-25$ per year & $11 \% 5-10$ years of experience \\
\hline & & $\begin{array}{l}15 \% \text { knee }+2 \text { other } \\
\text { joints surgeons }\end{array}$ & $33 \% 25-50$ per year & $\begin{array}{l}29 \% 10-20 \text { years of } \\
\text { experience }\end{array}$ \\
\hline & & & $27 \%$ 50-100 per year & $33 \%>20$ years of experience \\
\hline & & & $16 \%>100$ per year & \\
\hline \multirow[t]{4}{*}{ Grassi et al } & 2016 & NA & $35 \%<25$ per year & NA \\
\hline & & & $29 \%$ 25-50 per year & \\
\hline & & & $22 \% 50-100$ per year & \\
\hline & & & $11 \%>100$ per year & \\
\hline Budny et al & 2016 & $\begin{array}{l}89.4 \% \\
\text { Subspecialty trained }\end{array}$ & NA & NA \\
\hline \multirow[t]{4}{*}{ Vaishya et al } & 2016 & NA & $27 \%<25$ per year & NA \\
\hline & & & $27 \%$ 25-50 per year & \\
\hline & & & $15 \%$ 50-75 per year & \\
\hline & & & $31 \%>75$ per year & \\
\hline
\end{tabular}

Abbreviations: ACL, anterior cruciate ligament; NA, not assessed. 
Table 3 Evaluation of the survey quality and methodology

\begin{tabular}{|l|l|l|l|l|l|l|}
\hline Authors & Year & $\begin{array}{l}\text { Response rate } \\
\mathbf{5 0 \%}\end{array}$ & $\begin{array}{l}\text { Surveyed } \\
\mathbf{7 1 0 0}\end{array}$ & $\begin{array}{l}\text { Systematic } \\
\text { invitation }\end{array}$ & $\begin{array}{l}\text { Surveyed } \\
\text { experience }\end{array}$ & $\begin{array}{l}\text { Complete } \\
\text { results }\end{array}$ \\
\hline McRae et al & 2011 & $\mathrm{~N}$ & $\mathrm{Y}$ & $\mathrm{Y}$ & $\mathrm{Y}$ & $\mathrm{N}$ \\
\hline Mahnik et al & 2013 & $\mathrm{~N}$ & $\mathrm{~N}$ & $\mathrm{Y}$ & $\mathrm{Y}$ & $\mathrm{N}$ \\
\hline Ambra et al & 2015 & $\mathrm{~N}$ & $\mathrm{Y}$ & $\mathrm{N}$ & $\mathrm{Y}$ & $\mathrm{N}$ \\
\hline Kirwan et al & 2015 & $\mathrm{~N}$ & $\mathrm{~N}$ & $\mathrm{Y}$ & $\mathrm{Y}$ & $\mathrm{N}$ \\
\hline $\begin{array}{l}\text { Van der Bracht } \\
\text { et al }\end{array}$ & 2015 & $\mathrm{~N}$ & $\mathrm{~N}$ & $\mathrm{Y}$ & $\mathrm{Y}$ & $\mathrm{N}$ \\
\hline Grassi et al & 2016 & $\mathrm{~N}$ & $\mathrm{Y}$ & $\mathrm{Y}$ & $\mathrm{Y}$ & $\mathrm{Y}$ \\
\hline Budny et al & 2016 & $\mathrm{~N}$ & $\mathrm{Y}$ & $\mathrm{Y}$ & $\mathrm{N}$ & $\mathrm{N}$ \\
\hline Vaishya et al & 2016 & $\mathrm{Y}$ & $\mathrm{N}$ & $\mathrm{Y}$ & $\mathrm{Y}$ & $\mathrm{N}$ \\
\hline
\end{tabular}

Abbreviations: N, No; Y, yes.

However, due to the most recent results of ACL registries, extreme caution should be used while interpreting this trend, since an almost two-fold failure rate has been reported with AM technique compared with the transtibial. ${ }^{62}$ According to these data, the potential detrimental effect of the widespread use of AM technique should be accurately monitored in the following years through registries and long-term follow-up.

Analyzing the fixation methods, suspension systems for femoral fixation were the preferred choice in all but one survey, while screws were the preferred method for tibial fixation. Other variables such as tensioning, antibiotic and anti-thromboembolic prophylaxis tourniquet use, and drains were investigated scarcely among the surveys; therefore, no clear trends could be delineated. However, manual tensioning, administration of preoperative antibiotics, and tourniquet inflation seemed to be the preferred choices.

The main limitation of the present review is the limited number of included studies. However, applying strict inclusion criteria, we were able to select only the most recent surveys and to avoid including trends that could be considered not recent. Moreover, excluding multiple nations and international surveys, we had the opportunity to clearly describe national-specific trends and perspectives.

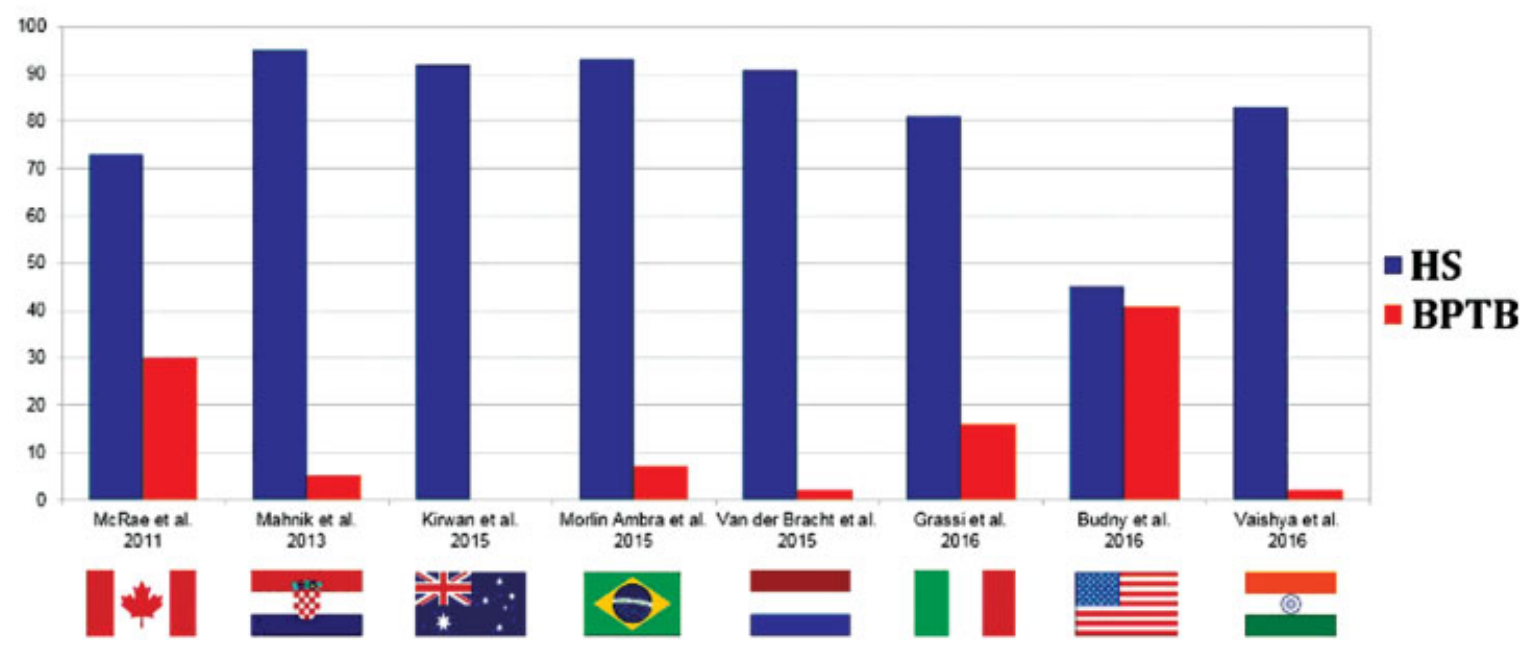

Fig. 2 Visual representation of the graft choice between HTs (blue bars) or BPTB (red bar) within the various national surveys. BPTB, bonepatellar-tendon-bone; HT, hamstring tendon. 


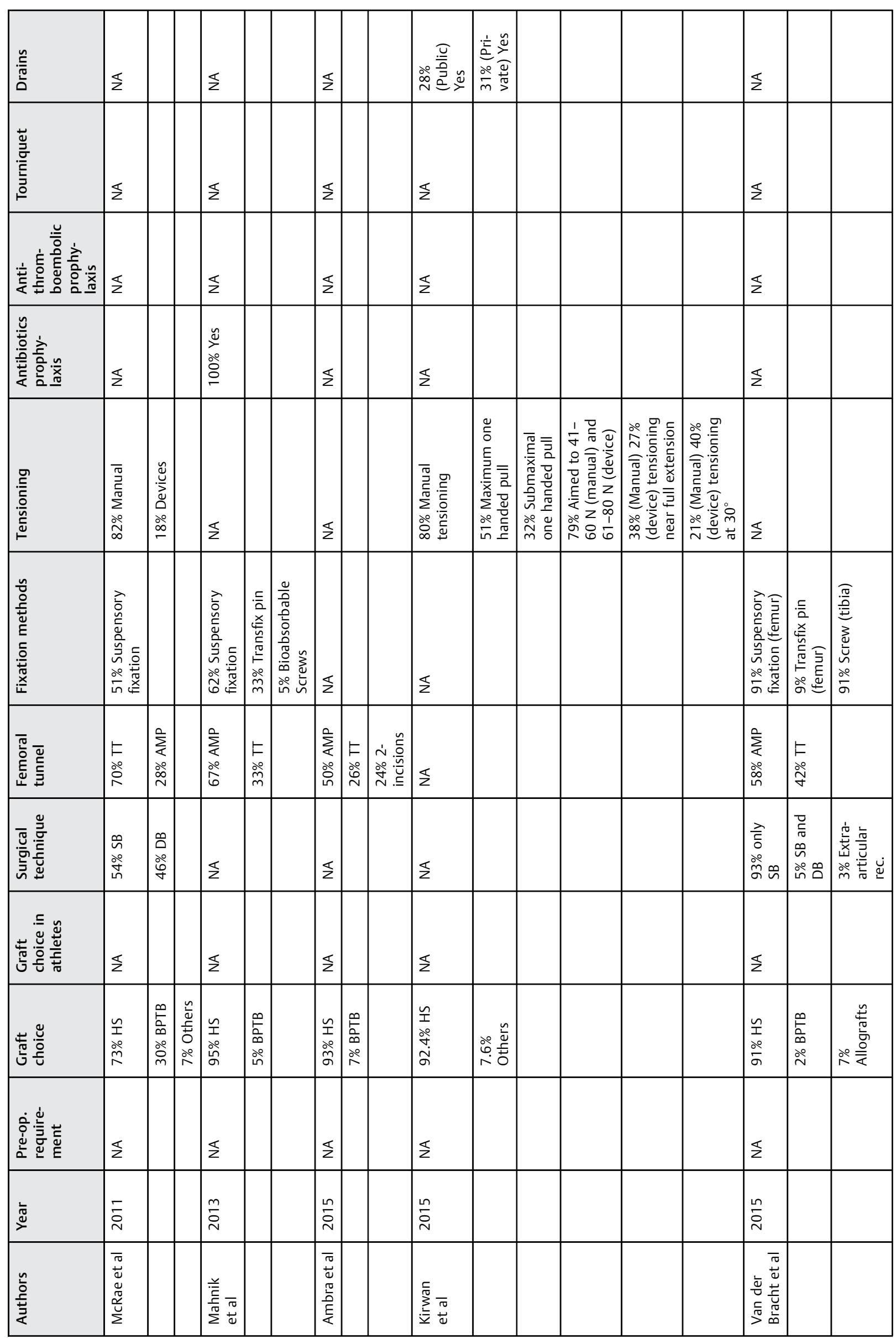



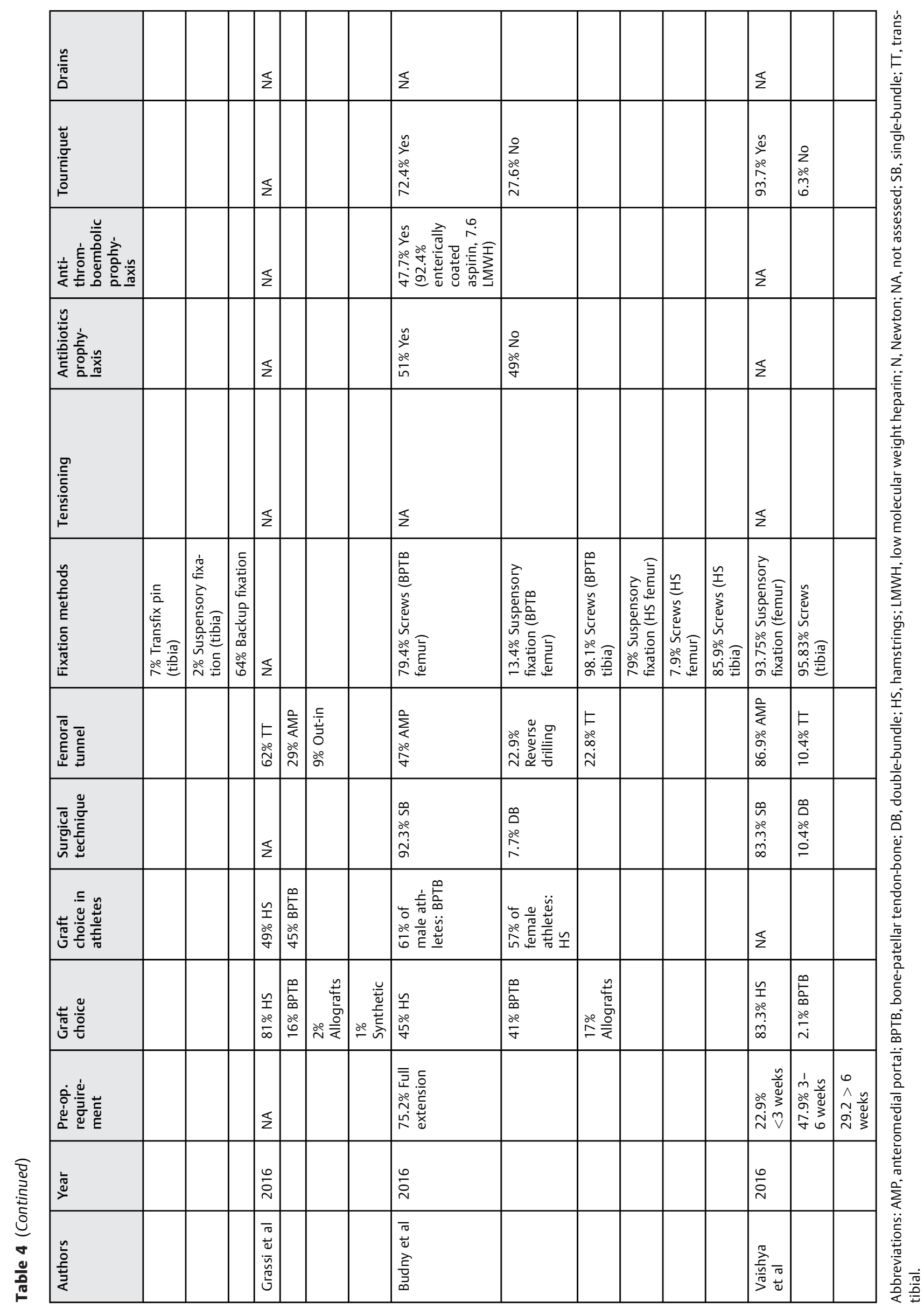


\section{Conclusion}

In conclusion, a trend toward the preference of HT autograft was registered in all the surveys; however, sport participation has been highlighted as an important variable for increased use of BPTB. Single-bundle reconstruction with AM portal technique and suspension femoral fixation and screws fixation for the tibia seem the preferred solution. Other variables such as tensioning, antibiotic and antithromboembolic prophylaxis, tourniquet use, and drains were investigated scarcely among the surveys; therefore, no clear trends could be delineated.

\section{Conflict of Interest}

None declared.

\section{Acknowledgments}

Corrado Bait, Aldo Ampollini, Christian Carulli, Riccardo Compagnoni, Paolo Ferrua, Marco Fravisini, Alberto Grassi, Giuseppe Mazzitelli, and Roberto Simonetta are members of the SIGASCOT arthroscopy committee.

\section{References}

1 Holm I, Oiestad BE, Risberg MA, Gunderson R, Aune AK. No differences in prevalence of osteoarthritis or function after open versus endoscopic technique for anterior cruciate ligament reconstruction: 12-year follow-up report of a randomized controlled trial. Am J Sports Med 2012;40(11):2492-2498

2 Shaerf DA, Pastides PS, Sarraf KM, Willis-Owen CA. Anterior cruciate ligament reconstruction best practice: a review of graft choice. World J Orthop 2014;5(01):23-29

3 Zeng C, Gao SG, Li H, et al. Autograft versus allograft in anterior cruciate ligament reconstruction: a meta-analysis of randomized controlled trials and systematic review of overlapping systematic reviews. Arthroscopy 2016;32(01):153-163

4 Xie X, Liu X, Chen Z, Yu Y, Peng S, Li Q. A meta-analysis of bonepatellar tendon-bone autograft versus four-strand hamstring tendon autograft for anterior cruciate ligament reconstruction. Knee 2015;22(02):100-110

5 Giron F, Cuomo P, Aglietti P, Bull AMJ, Amis AA. Femoral attachment of the anterior cruciate ligament. Knee Surg Sports Traumatol Arthrosc 2006;14(03):250-256

6 Tiamklang T, Sumanont S, Foocharoen T, Laopaiboon M. Doublebundle versus single-bundle reconstruction for anterior cruciate ligament rupture in adults. Cochrane Database Syst Rev 2012;11: CD008413

7 Riboh JC, Hasselblad V, Godin JA, Mather RC III. Transtibial versus independent drilling techniques for anterior cruciate ligament reconstruction: a systematic review, meta-analysis, and metaregression. Am J Sports Med 2013;41(11):2693-2702

8 Noh JH, Roh YH, Yang BG, Yi SR, Lee SY. Femoral tunnel position on conventional magnetic resonance imaging after anterior cruciate ligament reconstruction in young men: transtibial technique versus anteromedial portal technique. Arthroscopy 2013;29 (05):882-890

9 Matassi F, Sirleo L, Carulli C, Innocenti M. Anatomical anterior cruciate ligament reconstruction: transtibial versus outside-in technique: SIGASCOT Best Paper Award Finalist 2014. Joints 2015; 3(01):6-14

10 Sirleo L, Innocenti M, Innocenti M, Civinini R, Carulli C, Matassi F. Post-operative 3D CT feedback improves accuracy and precision in the learning curve of anatomic ACL femoral tunnel placement. Knee Surg Sports Traumatol Arthrosc 2018;26(02):468-477
11 Debieux P, Franciozi CES, Lenza M, et al. Bioabsorbable versus metallic interference screws for graft fixation in anterior cruciate ligament reconstruction. Cochrane Database Syst Rev 2016;7(07): CD009772

12 Carulli C, Matassi F, Soderi S, Sirleo L, Munz G, Innocenti M. Resorbable screw and sheath versus resorbable interference screw and staples for ACL reconstruction: a comparison of two tibial fixation methods. Knee Surg Sports Traumatol Arthrosc 2017;25(04):1264-1271

13 Moher D, Liberati A, Tetzlaff J, Altman DG; PRISMA Group. Preferred reporting items for systematic reviews and meta-analyses: the PRISMA statement. PLoS Med 2009;6(07):e1000097

14 Vascellari A, Grassi A, Combi A, Tomaello L, Canata GL, Zaffagnini $S$; SIGASCOT Sports Committee. Web-based survey results: surgeon practice patterns in Italy regarding anterior cruciate ligament reconstruction and rehabilitation. Knee Surg Sports Traumatol Arthrosc 2017;25(08):2520-2527

15 Astur DC, Batista RF, Gustavo A, Cohen M. Trends in treatment of anterior cruciate ligament injuries of the knee in the public and private healthcare systems of Brazil. Sao Paulo Med J 2013;131 (04):257-263

16 Chechik O, Amar E, Khashan M, Lador R, Eyal G, Gold A. An international survey on anterior cruciate ligament reconstruction practices. Int Orthop 2013;37(02):201-206

17 Moksnes H, Engebretsen L, Seil R. The ESSKA paediatric anterior cruciate ligament monitoring initiative. Knee Surg Sports Traumatol Arthrosc 2016;24(03):680-687

18 Petersen W, Zantop T. Return to play following ACL reconstruction: survey among experienced arthroscopic surgeons (AGA instructors). Arch Orthop Trauma Surg 2013;133(07): 969-977

19 Erickson BJ, Harris JD, Fillingham YA, et al. Orthopedic practice patterns relating to anterior cruciate ligament reconstruction in elite athletes. Am J Orthop 2015;44(12):E480-E485

20 Erickson BJ, Harris JD, Fillingham YA, et al. Anterior cruciate ligament reconstruction practice patterns by NFL and NCAA football team physicians. Arthroscopy 2014;30(06):731-738

21 Farber J, Harris JD, Kolstad K, McCulloch PC. Treatment of anterior cruciate ligament injuries by major league soccer team physicians. Orthop J Sports Med 2014;2(11):2325967114559892

22 Mall NA, Abrams GD, Azar FM, et al. Trends in primary and revision anterior cruciate ligament reconstruction among National Basketball Association team physicians. Am J Orthop 2014;43(06):267-271

23 Shafizadeh S, Jaecker V, Otchwemah R, Banerjee M, Naendrup JH. Current status of ACL reconstruction in Germany. Arch Orthop Trauma Surg 2016;136(05):593-603

24 Vaishya R, Agarwal AK, Ingole S, Vijay V. Current practice variations in the management of anterior cruciate ligament injuries in Delhi. J Clin Orthop Trauma 2016;7(03):193-199

25 Kirwan GW, Bourke MG, Chipchase L, Dalton PA, Russell TG. Graft tensioning practices in anterior cruciate ligament reconstruction amongst orthopaedic surgeons in Australia: a national survey. Arch Orthop Trauma Surg 2015;135(12):1733-1741

26 Ambra LF, Rezende FC, Xavier B, Shumaker FC, da Silveira Franciozi CE, Luzo MVM. Anterior cruciate ligament reconstruction: how do we perform it? Brazilian orthopedic surgeons' preference. Int Orthop 2016;40(03):595-600

27 Van der Bracht H, Goubau L, Stuyts B, Schepens A, Verdonk P, Victor J. Surgical management of anterior cruciate ligament injuries in Belgium anno 2013. Acta Orthop Belg 2015;81(04): 738-746

28 McRae SM, Chahal J, Leiter JR, Marx RG, Macdonald PB. Survey study of members of the Canadian Orthopaedic Association on the natural history and treatment of anterior cruciate ligament injury. Clin J Sport Med 2011;21(03):249-258

29 Budny J, Fox J, Rauh M, Fineberg M. Emerging trends in anterior cruciate ligament reconstruction. J Knee Surg 2017;30(01):63-69 
30 Mahnik A, Mahnik S, Dimnjakovic D, Curic S, Smoljanovic T, Bojanic I. Current practice variations in the management of anterior cruciate ligament injuries in Croatia. World J Orthop 2013;4(04):309-315

31 Grassi A, Vascellari A, Combi A, Tomaello L, Canata GL, Zaffagnini S; SIGASCOT Sports Committee. Return to sport after ACL reconstruction: a survey between the Italian Society of Knee, Arthroscopy, Sport, Cartilage and Orthopaedic Technologies (SIGASCOT) members. Eur J Orthop Surg Traumatol 2016;26(05):509-516

32 Suk M, Hanson B, Helfet DL. Evidence-based orthopedic surgery: is it possible? Orthop Clin North Am 2010;41(02):139-143

33 Mohtadi NG, Chan DS, Dainty KN, Whelan DB. Patellar tendon versus hamstring tendon autograft for anterior cruciate ligament rupture in adults. Cochrane Database Syst Rev 2011;(09): CD005960

34 Duquin TR, Wind WM, Fineberg MS, Smolinski RJ, Buyea CM. Current trends in anterior cruciate ligament reconstruction. J Knee Surg 2009;22(01):7-12

35 Baer GS, Harner CD. Clinical outcomes of allograft versus autograft in anterior cruciate ligament reconstruction. Clin Sports Med 2007;26(04):661-681

36 Reinhardt KR, Hetsroni I, Marx RG. Graft selection for anterior cruciate ligament reconstruction: a level I systematic review comparing failure rates and functional outcomes. Orthop Clin North Am 2010;41(02):249-262

37 Schoderbek RJ Jr, Treme GP, Miller MD. Bone-patella tendon-bone autograft anterior cruciate ligament reconstruction. Clin Sports Med 2007;26(04):525-547

38 Poolman RW, Abouali JA, Conter HJ, Bhandari M. Overlapping systematic reviews of anterior cruciate ligament reconstruction comparing hamstring autograft with bone-patellar tendon-bone autograft: why are they different? J Bone Joint Surg Am 2007;89 (07):1542-1552

39 Poolman RW, Farrokhyar F, Bhandari M. Hamstring tendon autograft better than bone patellar-tendon bone autograft in ACL reconstruction: a cumulative meta-analysis and clinically relevant sensitivity analysis applied to a previously published analysis. Acta Orthop 2007;78(03):350-354

40 Matsumoto A, Yoshiya S, Muratsu H, et al. A comparison of bonepatellar tendon-bone and bone-hamstring tendon-bone autografts for anterior cruciate ligament reconstruction. Am J Sports Med 2006;34(02):213-219

41 Maletis GB, Inacio MC, Desmond JL, Funahashi TT. Reconstruction of the anterior cruciate ligament: association of graft choice with increased risk of early revision. Bone Joint J 2013;95-B(05):623-628

42 Gifstad T, Foss OA, Engebretsen L, et al. Lower risk of revision with patellar tendon autografts compared with hamstring autografts: a registry study based on 45,998 primary ACL reconstructions in Scandinavia. Am J Sports Med 2014;42(10):2319-2328

43 Persson A, Fjeldsgaard $\mathrm{K}$, Gjertsen JE, et al. Increased risk of revision with hamstring tendon grafts compared with patellar tendon grafts after anterior cruciate ligament reconstruction: a study of 12,643 patients from the Norwegian Cruciate Ligament Registry, 2004-2012. Am J Sports Med 2014;42(02):285-291

44 Tiamklang T, Sumanont S, Foocharoen T, Laopaiboon M. Doublebundle versus single-bundle reconstruction for anterior cruciate ligament rupture in adults. Cochrane Database Syst Rev 2012;11: CD008413

45 Herbort M, Lenschow S, Fu FH, Petersen W, Zantop T. ACL mismatch reconstructions: influence of different tunnel placement strategies in single-bundle ACL reconstructions on the knee kinematics. Knee Surg Sports Traumatol Arthrosc 2010;18(11): 1551-1558

46 Kato Y, Ingham SJ, Kramer S, Smolinski P, Saito A, Fu FH. Effect of tunnel position for anatomic single-bundle ACL reconstruction on knee biomechanics in a porcine model. Knee Surg Sports Traumatol Arthrosc 2010;18(01):2-10

47 Kocher MS, Steadman JR, Briggs KK, Sterett WI, Hawkins RJ. Relationships between objective assessment of ligament stability and subjective assessment of symptoms and function after anterior cruciate ligament reconstruction. Am J Sports Med 2004;32 (03):629-634

48 Chambat P, Guier C, Sonnery-Cottet B, Fayard JM, Thaunat M. The evolution of $A C L$ reconstruction over the last fifty years. Int Orthop 2013;37(02):181-186

49 Zantop T, Kubo S, Petersen W, Musahl V, Fu FH. Current techniques in anatomic anterior cruciate ligament reconstruction. Arthroscopy 2007;23(09):938-947

50 Voos JE, Musahl V, Maak TG, Wickiewicz TL, Pearle AD. Comparison of tunnel positions in single-bundle anterior cruciate ligament reconstructions using computer navigation. Knee Surg Sports Traumatol Arthrosc 2010;18(09):1282-1289

51 Brophy RH, Wright RW, Matava MJ. Cost analysis of converting from single-bundle to double-bundle anterior cruciate ligament reconstruction. Am J Sports Med 2009;37(04):683-687

52 Pearle AD, Shannon FJ, Granchi C, Wickiewicz TL, Warren RF. Comparison of 3-dimensional obliquity and anisometric characteristics of anterior cruciate ligament graft positions using surgical navigation. Am J Sports Med 2008;36(08):1534-1541

53 Strauss EJ, Barker JU, McGill K, Cole BJ, Bach BR Jr, Verma NN. Can anatomic femoral tunnel placement be achieved using a transtibial technique for hamstring anterior cruciate ligament reconstruction? Am J Sports Med 2011;39(06):1263-1269

54 Bird JH, Carmont MR, Dhillon M, et al. Validation of a new technique to determine midbundle femoral tunnel position in anterior cruciate ligament reconstruction using 3-dimensional computed tomography analysis. Arthroscopy 2011;27(09): 1259-1267

55 Brophy RH, Pearle AD. Single-bundle anterior cruciate ligament reconstruction: a comparison of conventional, central, and horizontal single-bundle virtual graft positions. Am J Sports Med 2009;37(07):1317-1323

56 Meredick RB, Vance KJ, Appleby D, Lubowitz JH. Outcome of single-bundle versus double-bundle reconstruction of the anterior cruciate ligament: a meta-analysis. Am J Sports Med 2008;36 (07):1414-1421

57 Verhelst L, Van Der Bracht H, Oosterlinck D, Bellemans J. ACL repair with a single or double tunnel: a comparative laboratory study of knee stability using computer navigation. Acta Orthop Belg 2012;78(06):771-778

58 Hettrich CM, Dunn WR, Reinke EK, Spindler KP; MOON Group. The rate of subsequent surgery and predictors after anterior cruciate ligament reconstruction: two- and 6-year follow-up results from a multicenter cohort. Am J Sports Med 2013;41(07):1534-1540

59 Hosseini A, Lodhia P, Van de Velde SK, et al. Tunnel position and graft orientation in failed anterior cruciate ligament reconstruction: a clinical and imaging analysis. Int Orthop 2012;36(04): 845-852

60 Marchant BG, Noyes FR, Barber-Westin SD, Fleckenstein C. Prevalence of nonanatomical graft placement in a series of failed anterior cruciate ligament reconstructions. Am J Sports Med 2010;38(10):1987-1996

61 Arno S, Bell CP, Alaia MJ, et al. Does Anteromedial Portal Drilling Improve Footprint Placement in Anterior Cruciate Ligament Reconstruction? Clin Orthop Relat Res 2016;474(07):1679-1689

62 Rahr-Wagner L, Thillemann TM, Pedersen AB, Lind MC. Increased risk of revision after anteromedial compared with transtibial drilling of the femoral tunnel during primary anterior cruciate ligament reconstruction: results from the Danish Knee Ligament Reconstruction Register. Arthroscopy 2013;29(01):98-105 